\title{
Confounding and Statistical Significance of Indirect Effects: Childhood Adversity, Education, Smoking, and Anxious and Depressive Symptomatology
}

\author{
Mashhood Ahmed Sheikh * \\ Health Services Research Unit, Department of Community Medicine, University of Tromsø, Tromsø, Norway
}

The life course perspective, the risky families model, and stress-and-coping models provide the rationale for assessing the role of smoking as a mediator in the association between childhood adversity and anxious and depressive symptomatology (ADS) in adulthood. However, no previous study has assessed the independent mediating role of smoking in the association between childhood adversity and ADS in adulthood.

OPEN ACCESS

Edited by:

Sergio Machado,

Federal University of Rio de Janeiro,

Brazil

Reviewed by:

Marco Innamorati,

Università Europea di Roma, Italy Maria Isabel Brazil Protasio,

Prefeitura da Cidade do Rio de

Janeiro, Brazil

*Correspondence:

Mashhood Ahmed Sheikh

mashhood.a.sheikh@uit.no

Specialty section:

This article was submitted to

Quantitative Psychology and

Measurement,

a section of the journal

Frontiers in Psychology

Received: 28 April 2017

Accepted: 18 July 2017

Published: 02 August 2017

Citation:

Sheikh MA (2017) Confounding and

Statistical Significance of Indirect Effects: Childhood Adversity,

Education, Smoking, and Anxious and Depressive Symptomatology.

Front. Psychol. 8:1317.

doi: 10.3389/fpsyg.2017.01317
Moreover, the importance of mediator-response confounding variables has rarely been demonstrated empirically in social and psychiatric epidemiology. The aim of this paper was to (i) assess the mediating role of smoking in adulthood in the association between childhood adversity and ADS in adulthood, and (ii) assess the change in estimates due to different mediator-response confounding factors (education, alcohol intake, and social support). The present analysis used data collected from 1994 to 2008 within the framework of the Troms $\varnothing$ Study $(N=4,530)$, a representative prospective cohort study of men and women. Seven childhood adversities (low mother's education, low father's education, low financial conditions, exposure to passive smoke, psychological abuse, physical abuse, and substance abuse distress) were used to create a childhood adversity score. Smoking status was measured at a mean age of 54.7 years (Tromsø IV), and ADS in adulthood was measured at a mean age of 61.7 years (Tromsø V). Mediation analysis was used to assess the indirect effect and the proportion of mediated effect (\%) of childhood adversity on ADS in adulthood via smoking in adulthood. The testretest reliability of smoking was good (Kappa: $0.67,95 \% \mathrm{Cl}$ : 0.63; 0.71) in this sample. Childhood adversity was associated with a $10 \%$ increased risk of smoking in adulthood (Relative risk: 1.10, 95\% Cl: 1.03; 1.18), and both childhood adversity and smoking in adulthood were associated with greater levels of ADS in adulthood $(p<0.001)$. Smoking in adulthood did not significantly mediate the association between childhood adversity and ADS in adulthood. However, when education was excluded as a mediator-response confounding variable, the indirect effect of childhood adversity on ADS in adulthood was statistically significant $(0<0.05)$. This study shows that a careful inclusion of potential confounding variables is important when assessing mediation.

Keywords: direct effect, proportion of mediated effect, decomposition, mediation, confounding, anxiety, depression, longitudinal 


\section{INTRODUCTION}

In social and psychiatric epidemiology, one of the most studied associations is that between childhood adversity, smoking, and health-related outcomes in adulthood (Patten et al., 2016; Sheikh et al., 2016a; Tani et al., 2016; Sheikh, 2017). Previous studies have shown that childhood adversity increases the risk of certain adult behaviors that can increase the risk of anxiety and depression (Sheikh et al., 2016a; Tani et al., 2016). In particular, smoking has often been associated with childhood adversity (Power and Hertzman, 1997; Anda et al., 1999; Gilman et al., 2003; Kestilä et al., 2006; Sheikh et al., 2016a) and with anxiety and depression in later life (Fluharty et al., 2016; Le et al., 2016; Sheikh et al., 2016a).

Chronic stress (the cumulative load of day-to-day stresses) in childhood caused by socioeconomic and psychosocial adversity may foster impaired self-regulation, which in turn may affect unhealthy lifestyle choices such as smoking (McEwen, 2000; Mulvihill, 2005; Miller et al., 2011; Le et al., 2016; Sheikh, 2017). Previous psychological research has shown that childhood adversity is associated with higher impulsivity in adolescence (Lau et al., 1999; Robbins and Bryan, 2004; Miller et al., 2011). In turn, adolescents with higher impulsivity are more likely to smoke (Robbins and Bryan, 2004; Balevich et al., 2013; Mitchell and Potenza, 2014; Stautz et al., 2016). Other studies have shown that childhood adversity is associated with smoking in adulthood independent of DSM-IV psychopathology (Spratt et al., 2009; Fuller-Thomson et al., 2013). Smoking may serve as self-medication, as a coping strategy to induce a relaxed state (Warburton, 1987; Mulvihill, 2005), or as a method of compensating for deficiencies in social and emotional development (Repetti et al., 2002; Gould and Martindale, 2007; Strine et al., 2012; Prock, 2015). Social and emotional impairments, and deficits in interpersonal development and affect regulation, have also been proposed as consequences of childhood adversity (Kim and Cicchetti, 2010; Moretti and Craig, 2013; Dvir et al., 2014; Stikkelbroek et al., 2016). The life course perspective (Elder, 1985), the risky families model (Repetti et al., 2002), and stress-and-coping models (Pearlin et al., 2005) provide the rationale for assessing the role of smoking as a mediator in the association between childhood adversity and anxious and depressive symptomatology (ADS) in adulthood.

Analytically, if the magnitude of the association between smoking and ADS in adulthood remains strong after controlling for childhood adversity and confounding variables, and the direct effect of childhood adversity (adjusted for smoking and confounding variables) on ADS in adulthood remains strong, it indicates that both the initial stressor (childhood adversity) and the secondary stressor (smoking) exert a unique negative effect on ADS in adulthood. However, if the magnitude of the association between childhood adversity and ADS in adulthood after controlling for smoking and confounding variables is close to null, and the association between smoking and ADS remains strong (after controlling for childhood adversity and confounding variables), it indicates that smoking influences ADS in place of childhood adversity (i.e., almost all of the influence of childhood adversity on ADS in adulthood is mediated by smoking). However, the causal interpretation of these inferences are subject to a number of assumptions (Robins and Greenland, 1992; Cole and Hernán, 2002; Sheikh et al., 2016a,b; Sheikh, 2017).

The association between childhood adversity and ADS in adulthood is likely confounded by genetic dispositions (Sheikh, 2017). Indeed, almost 40-70\% (depending on the stringency of the definition) of one's risk of anxiety and depression is genetically determined (Kendler et al., 1993a; McGuffin et al., 1996; Heim and Binder, 2012). Parental history of mental and physical chronic conditions may serve as a crude proxy for genetic dispositions (Sheikh, 2017). Experts in mediation analysis have repeatedly pointed out that an unbiased decomposition of total effects into direct and indirect effects relies on a number of assumptions, including no unmeasured (or unaccounted for) mediator-response confounding variables (Robins and Greenland, 1992; Cole and Hernán, 2002). Several studies have shown that smoking is closely associated with education, alcohol intake, and social support (Donovan and Jessor, 1985; Shiffman et al., 1994; Ary et al., 1999; Haustein, 2006; Gilman et al., 2008; Jackson et al., 2010). Other reports suggest that these factors are likely associated with childhood adversity and ADS later in life (Kauhanen et al., 2011; Lemos et al., 2012; Kim et al., 2013; Mersky et al., 2013; Campbell et al., 2016; Nurius et al., 2016). Consequently, several studies have indicated that education, alcohol intake, and social support mediate the association between childhood adversity and ADS in adulthood (Nurius et al., 2015; Openshaw et al., 2015; Shevlin et al., 2015; Lê-Scherban et al., 2016; Muller, 2016; Ni et al., 2016; Sheikh et al., 2016a,b; Tani et al., 2016; Korhonen et al., 2017; Kwon and Park, 2017; Lee et al., 2017; Markkula et al., 2017; Wielaard et al., 2017) and suggested that these are important mediator-response confounding factors that must be included in analytical models in order to assess the indirect effect of childhood adversity on ADS in adulthood via smoking. It is plausible that if the mediating role of smoking is assessed without controlling for key mediator-response confounding variables, the observed indirect effect may be biased upwards (or will be statistically significant), not because smoking alone mediates the association between childhood adversity and ADS, but because of the correlation between smoking and an unmeasured (or unaccounted for) mediator-response confounder. Therefore, controlling for potential mediator-response confounding factors (e.g., education, alcohol intake, and social support) is crucial in order to infer that smoking "alone" mediates the association between childhood adversity and ADS in adulthood.

Often a mediator-response confounder goes unmeasured; when this happens one basically has to invent a scenario to assess how an unmeasured mediator-response confounder would affect the direct and indirect effects. Indeed, the sensitivity analysis that has been proposed for this (VanderWeele and Arah, 2011; VanderWeele, 2015) consists of inventing an unmeasured mediator-response confounder, as well as its "unobserved" association with the exposure, mediator, and response. This invented information is then used to assess how much the direct and indirect effects would change if that mediator-response confounder was measured. This process of using invented 
information is unlikely to have any practical significance, unless empirical studies can show convincing evidence that accounting for such a mediator-response confounder significantly affects the direct and indirect effects.

The aim of the present study was (i) to assess the mediating role of smoking in the association between childhood adversity and ADS in adulthood, and (ii) to assess the change in estimates due to different mediator-response confounding factors (education, alcohol intake, and social support).

\section{METHODS}

\section{Study Population}

The Tromsø Study is a longitudinal prospective cohort study and its participants are considered representative of the adult population residing in the municipality of Tromsø (Jacobsen et al., 2012). Between 1974 and 2008, six waves of the Tromsø Study were conducted (referred to as Tromsø I-VI) (Jacobsen et al., 2012). The present analysis includes data collected from 1994 to 2008.

To be eligible for the present analyses, participants had to have attended all of the following waves: Tromsø IV (19941995), Tromsø V (2001-2002), and Tromsø VI (2007-2008) $(N=4,530)$. The study sample included participants aged 2574 years at Tromsø IV, 32-81 years at Tromsø V, and 38-87 years at Tromsø VI.

\section{Ethical Approval}

This investigation was carried out in accordance with the latest version of the Declaration of Helsinki. The Tromsø Study has been approved by the Regional Committee for Medical and Health Research Ethics, the Data Inspectorate, and the Norwegian Directorate of Health. Written informed consent was obtained from all individual participants included in the study.

\section{Study Variables \\ Exposure (Childhood Adversity)}

The present analysis used seven indicators of childhood adversity (low mother's education, low father's education, low childhood financial conditions, three kinds of adverse childhood experiences, and exposure to passive smoke in childhood) measured retrospectively in Tromsø IV and Tromsø VI, to create a childhood adversity score. Participants received 1 point for each adversity that was present in their childhood, thus scores ranged from 0 to 7 . Independent associations between each childhood adversity and ADS has been shown in earlier studies that also used data from the Tromsø Study (Sheikh et al., 2014, 2016a,b).

Parental education was used as an indicator of social background. Mother's and father's education was obtained separately on a 5-level scale in Tromsø VI as: (1) college or university (4 years or more); (2) college or university (less than 4 years); (3) high school diploma; (4) vocational school or technical school; and (5) primary and secondary school or similar (i.e., 7-10 years of schooling). The lowest parental education level, i.e., parental primary and secondary school or similar, was considered a childhood adversity. Childhood financial conditions was used as the indicator of economic background, and was obtained in Tromsø IV as: "How was your family's financial situation when you were a child?" Participants replied using a 4-point scale ranging from very difficult (1) to very good (4). Those who answered difficult or very difficult were considered to have this childhood adversity. The test-retest reliability of childhood financial conditions was good (Kappa $a_{\text {weighted: }}$ 0.61, 95\% confidence interval [CI] 0.59; 0.63) in Tromsø study (Sheikh et al., 2016b; Sheikh, 2017). Information on adverse childhood experiences were obtained in Tromsø VI as: "Have you over a long period experienced any of the following? (as a child)," followed by three types of traumatic experiences: (i) being tormented, or threatened with violence; (ii) being beaten, kicked, or the victim of other types of violence; and (iii) someone in your close family using alcohol or drugs in such a way that caused you worry. Each of these adverse childhood experiences was considered a childhood adversity. The internal reliability of these adverse childhood experiences was good in the Tromsø Study (Sheikh, 2017). Exposure to passive smoke in childhood was obtained in Tromsø IV as: "Did any of the adults smoke at home while you were growing up?" Those reporting "yes" were considered to have this childhood adversity. The testretest reliability of exposure to passive smoke in childhood was good (Kappa: 0.76, 95\% CI: 0.74; 0.78) in this sample (Sheikh, 2017). A composite variable was constructed as sum of the seven childhood adversities (mean: 2.91, SD: 1.11).

\section{Mediator (Daily Smoking)}

Daily smoking was measured in Tromsø IV (mean age of participants: 54.7 years) as: "Do you smoke cigarettes daily?" (yes $=1 /$ no $=0$ ). Although the smoking status of the participants may change during follow-up, the test-retest reliability was good (Kappa: 0.67, 95\% CI: 0.63; 0.71) in this sample.

Response (Anxious and Depressive Symptomatology) Anxious and depressive symptomatology was measured in the Tromsø V (mean age of participants: 61.7 years) using the Hopkins Symptom Checklist (HSCL-10). HSCL-10 consists of 10 items on a four-point scale, ranging from not at all (1) to extremely (4). The HSCL-10 had an acceptable degree of internal consistency in this sample (Cronbach's alpha: 0.86, mean inter-item correlation: 0.42 , McDonald's omega coefficient for composite reliability: 0.87). In accordance with Strand et al. (2003), an HSCL-10 score between 1 and 4 was assigned by dividing the total score (sum of the 10 indicators) by the total number of items, where 4 represented the highest and 1 represented the lowest score for ADS (mean: 1.25, standard deviation [SD]: 0.33). An HSCL-10 score of 1.85 has been proposed as a cut-to predict diagnosed anxiety and depression (Strand et al., 2003; Kvamme et al., 2011; Sheikh et al., 2016a). Earlier studies using data from the Tromsø Study have suggested that over $9.3 \%$ of the adult population (age 30-89 years) in Tromsø could be classified as clinically significant cases of ADS with this cut-off (Sheikh et al., 2016a). Based on information from clinical interviews, previous literature has indicated that 50-60\% of cases detected by the HSCL-10 could actually be categorized as having clinically significant anxiety and depression (Strand et al., 2003; Kvamme et al., 2011). 


\section{Confounding Variables}

The potential confounding variables age, gender, living in Norway at age 1 year, history of psychological problems in the mother/father, parental history of heart attack, angina pectoris, cerebral stroke/brain hemorrhage, osteoporosis, stomach/duodenal ulcer, asthma, diabetes, and dementia were chosen based on a priori knowledge of the association between childhood adversity, smoking and ADS (Wender et al., 1986; Kaslow et al., 1994; Kaplow and Widom, 2007; Pollak, 2008; Bet et al., 2009; Miller et al., 2011; Melas et al., 2013; Agerup et al., 2015; Plant et al., 2015; South et al., 2015; Fandiño-Losada et al., 2016; Sheikh, 2017). Valid information on age and gender was obtained from Statistics Norway by using the unique personal identification number of each participant. The test-retest reliability of history of psychological problems of the mother and father in Tromsø Study were Kappa: 0.57 (95\% CI: 0.52; 0.62) and Kappa: 0.61 (95\% CI: 0.53; 0.69), respectively (Sheikh, 2017).

\section{Mediator-Response Confounding Factors}

Previous research suggests that education, alcohol intake, and social support are potential smoking-ADS confounding factors (Lahelma et al., 2006; Comijs et al., 2007; Eugenia Alvarado et al., 2007; Vranceanu et al., 2007; Mossakowski, 2008; Nicholson et al., 2008; Banou et al., 2009; Powers et al., 2009; Hill et al., 2010; Korkeila et al., 2010; McKenzie et al., 2010, 2011; Ford et al., 2011; Salazar et al., 2011). Participant's education was obtained on the same 5-level scale used for parental education (mean: 3.87, SD: 1.35). Although the education level of the participants may increase during 13 years of follow-up, the test-retest reliability was very good (Kappa: 0.91, 95\% CI: 0.91; 0.92 ) in this sample. Alcohol intake was measured with four indicators: alcohol frequency (times/month), beer frequency (times/fortnight), wine frequency (times/fortnight), and spirit frequency (times/fortnight). Social support was measured with two indicators: number of friends and perceived social support.

\section{Statistical Analysis}

All statistical analyses were conducted using Stata version 14 . Kappa agreement was used to assess the test-retest reliability of variables that were measured in at least two waves of the Troms $\varnothing$ Study. The kappa coefficients summarize the total agreement beyond that expected by chance (Sheikh et al., 2016c). Ninetyfive percent confidence intervals (CIs) for kappa statistic were estimated with the analytical method (Fleiss et al., 2003) in Stata (Reichenheim, 2004). Established benchmarks (Sheikh et al., 2016c) for rating the strength of kappa agreements (poor: $<0.20$; fair: $>0.20$ to $\leq 0.40$; moderate: $>0.40$ to $\leq 0.60$; good: $>0.60$ to $\leq 0.80$; and very good: $>0.80$ to $\leq 1.00$ ) were used.

Missing values were generated with multiple imputation (with chained equations) to avoid any bias in the association of interest introduced by excluding individuals with missing data. One hundred multiple datasets were generated to help account for the uncertainty in the imputation procedure. In order to increase the predictive power of the imputation procedure, all indicators of the HSCL-10 were included in the imputation models. A comparison between the complete-case (excluding missing) and the imputed dataset is presented with proportions (\%), and mean (standard error, SE) (Table 1). Both the unadjusted (crude) and adjusted estimates are presented.

The association between childhood adversity and smoking in adulthood was assessed by Poisson regression analysis with a robust error variance (Zou, 2004). The association between smoking in adulthood and ADS in adulthood was assessed by ordinary least square (OLS) regression analysis. Relative risks (RRs), OLS estimates ( $\beta$ ) and corresponding 95\% CIs are presented. A nonlinear association between childhood adversity and ADS in adulthood was observed. The cubic form was identified as the best fitting fractional polynomial; therefore, the cubic form was used in all analysis, to account for the nonlinear association. Childhood adversity was transformed as:

Childhood adversity $_{\text {transformed }}=\left(1+\right.$ Childhood adversity $\left.^{3}\right) / 100$

\section{Assessing Direct and Indirect Effects (via Smoking) of Childhood Adversity on Anxious and Depressive Symptomatology in Adulthood}

Mediation analysis with the difference-in-coefficients method (Shrout and Bolger, 2002; MacKinnon et al., 2007; Sheikh et al., 2016b) was used. No statistically significant multiplicative interaction between childhood adversity and smoking $(p>0.1)$ was observed in this sample. Four estimates are presented: total effects (adjusted for confounding variables), direct effects (adjusted for confounding variables and smoking), indirect effects (difference between total effect and direct effect), and proportion mediated (\%). Smoking in adulthood was included in the models to assess the indirect effect and the proportion of mediated effect (\%). If smoking in adulthood is an important mediator of the association between childhood adversity and ADS in adulthood, the effects of childhood adversity ( $\left.\beta_{\text {Total Effect }}\right)$ should decline when smoking in adulthood is added to the model. Since education may be an intermediate confounder in the $\mathrm{CA} \rightarrow$ smoking $\rightarrow \mathrm{ADS}$ association, we assessed whether education was a mediator between CA and smoking. However, the indirect effect of CA on smoking (via education) was not statistically significant. Therefore, we ruled out the possibility that education is an intermediate confounder in this study sample (data not shown).

SEs were derived with bootstrapping for hypothesis testing, and $95 \%$ CIs are presented. Furthermore, in order to assess whether the proportion of mediated effects varies due to the smoking-ADS confounding factors included in the model, each smoking-ADS confounding factor was omitted from the models, one-by-one.

\section{RESULTS}

The majority of the participants in our study sample were aged 55 and over (56.2\%) in Tromsø IV and were female (59.2\%) (Table 1). The average number of childhood adversities in this sample was 2.91 (SE: 0.02) (Table 1). Only 2.1\% of the participants reported none of the childhood adversities considered in this study, while $8.4 \%$ of the participants had 
TABLE 1 | General characteristics of the study sample $(n=4,530)$.

\begin{tabular}{|c|c|c|c|}
\hline \multirow{2}{*}{\multicolumn{2}{|c|}{ Characteristics }} & $\begin{array}{l}\text { Complete-case } \\
\text { dataset }\end{array}$ & $\begin{array}{l}\text { Imputed } \\
\text { data }\end{array}$ \\
\hline & & $n(\%)$ & $(\%)$ \\
\hline \multicolumn{4}{|c|}{$\begin{array}{l}\text { EXPOSURE-MEDIATOR, MEDIATOR-RESPONSE, AND EXPOSURE- } \\
\text { RESPONSE CONFOUNDING VARIABLES }\end{array}$} \\
\hline \multirow[t]{6}{*}{ Age (in 1994) } & Mean (SE) & $54.69(0.15)$ & $-{ }^{\mathrm{b}}$ \\
\hline & 25-34 & $302(6.7)$ & $-{ }^{b}$ \\
\hline & $35-44$ & $352(7.8)$ & $-{ }^{b}$ \\
\hline & $45-54$ & 1,327 (29.3) & $-\mathrm{b}$ \\
\hline & $55-64$ & $1,852(40.8)$ & $-{ }^{b}$ \\
\hline & $65-74$ & $697(15.4)$ & $-\mathrm{b}$ \\
\hline \multirow[t]{2}{*}{ Gender } & Male & $1,849(40.8)$ & $-{ }^{b}$ \\
\hline & Female & 2,681 (59.2) & $-{ }^{b}$ \\
\hline \multirow[t]{2}{*}{ Living in Norway at age 1 year ${ }^{a}$} & Yes & 4,081 (98.4) & 98.4 \\
\hline & No & $66(1.6)$ & 1.6 \\
\hline \multirow{2}{*}{$\begin{array}{l}\text { History of psychological } \\
\text { problems, mother }\end{array}$} & Yes & $261(5.8)$ & $-b$ \\
\hline & No & 4,269 (94.2) & $-{ }^{\mathrm{b}}$ \\
\hline \multirow{2}{*}{$\begin{array}{l}\text { History of psychological } \\
\text { problems, father }\end{array}$} & Yes & $114(2.5)$ & $-\mathrm{b}$ \\
\hline & No & 4,416 (97.5) & $-{ }^{b}$ \\
\hline \multirow[t]{2}{*}{ Parental history of heart attack } & Yes & $566(12.5)$ & $-b$ \\
\hline & No & $3,964(87.5)$ & $-{ }^{b}$ \\
\hline \multirow{2}{*}{$\begin{array}{l}\text { Parental history of angina } \\
\text { pectoris }\end{array}$} & Yes & $978(21.6)$ & $-\mathrm{b}$ \\
\hline & No & $3,552(78.4)$ & $-{ }^{b}$ \\
\hline \multirow{2}{*}{$\begin{array}{l}\text { Parental history of cerebral } \\
\text { stroke/brain hemorrhage }\end{array}$} & Yes & $1,043(23.0)$ & $-b$ \\
\hline & No & $3,487(77.0)$ & $-b$ \\
\hline \multirow[t]{2}{*}{ Parental history of osteoporosis } & Yes & $330(7.3)$ & $-{ }^{b}$ \\
\hline & No & $4,200(92.7)$ & $-\mathrm{b}$ \\
\hline \multirow{2}{*}{$\begin{array}{l}\text { Parental history of stomach or } \\
\text { duodenal ulcer }\end{array}$} & Yes & $559(12.3)$ & $-\mathrm{b}$ \\
\hline & No & $3,971(87.7)$ & $-{ }^{b}$ \\
\hline \multirow[t]{2}{*}{ Parental history of asthma } & Yes & $455(10.0)$ & $-\mathrm{b}$ \\
\hline & No & $4,075(90.0)$ & $-\mathrm{b}$ \\
\hline \multirow[t]{2}{*}{ Parental history of diabetes } & Yes & $6[-0.1 \mathrm{pt}] 71(14.8)$ & $-\mathrm{b}$ \\
\hline & No & $3,859(85.2)$ & $-{ }^{\mathrm{b}}$ \\
\hline \multirow[t]{2}{*}{ Parental history of dementia } & Yes & $459(10.1)$ & $-\mathrm{b}$ \\
\hline & No & $4,071(89.9)$ & $-{ }^{b}$ \\
\hline \multicolumn{4}{|c|}{ MEDIATOR-RESPONSE CONFOUNDING VARIABLES } \\
\hline Education ${ }^{\mathrm{a}, \mathrm{c}}$ & Mean (SE) & $3.87(0.02)$ & $3.87(0.02)$ \\
\hline $\begin{array}{l}\text { Alcohol frequency } \\
\text { (times/month) }^{\mathrm{a}}\end{array}$ & Mean (SE) & $3.00(0.07)$ & $2.90(0.06)$ \\
\hline $\begin{array}{l}\text { Beer frequency } \\
\text { (glasses/fortnight) }^{\mathrm{a}}\end{array}$ & Mean (SE) & $1.21(0.04)$ & $1.14(0.04)$ \\
\hline $\begin{array}{l}\text { Wine frequency } \\
\text { (glasses/fortnight) }^{\mathrm{a}}\end{array}$ & Mean (SE) & $1.58(0.05)$ & $1.52(0.04)$ \\
\hline $\begin{array}{l}\text { Spirit frequency } \\
\text { (glasses/fornight) }^{a}\end{array}$ & Mean (SE) & $1.31(0.04)$ & $1.24(0.04)$ \\
\hline Number of friends ${ }^{a}$ & Mean (SE) & $5.10(0.08)$ & $5.11(0.08)$ \\
\hline \multirow[t]{2}{*}{ Perceived social support ${ }^{a}$} & $\begin{array}{l}\text { Socially } \\
\text { isolated }\end{array}$ & $669(16.1)$ & 16.1 \\
\hline & $\begin{array}{l}\text { Not socially } \\
\text { isolated }\end{array}$ & 3,485 (83.9) & 83.9 \\
\hline \multicolumn{4}{|l|}{ EXPOSURE } \\
\hline 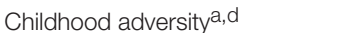 & & & \\
\hline
\end{tabular}

(Continued)
TABLE 1 | Continued

\begin{tabular}{lccc}
\hline Characteristics & & $\begin{array}{c}\text { Complete-case } \\
\text { dataset }\end{array}$ & $\begin{array}{c}\text { Imputed } \\
\text { data }\end{array}$ \\
\cline { 3 - 4 } & & $\boldsymbol{n}(\%)$ & (\%) \\
\hline & 0 & $78(2.1)$ & 2.0 \\
& 1 & $311(8.4)$ & 8.0 \\
& 2 & $794(21.3)$ & 21.5 \\
& 3 & $1,462(39.3)$ & 39.5 \\
& 4 & $897(24.1)$ & 24.2 \\
& 5 & $133(3.6)$ & 3.4 \\
MEDIATOR & 6 & $46(1.2)$ & 1.2 \\
Daily smoking & & $4(0.1)$ & 0.1 \\
& 7 & $1,312(29.0)$ & 29.0 \\
RESPONSE & Yes & $3,213(71.0)$ & 71.0 \\
Anxious and depressive & No & $1.22(0.01)$ & $1.25(0.01)$ \\
symptomatology (HSCL-10 & Mean (SE) & & \\
score) & & & \\
\hline
\end{tabular}

a The numbers for some variables do not add up to 4,530 due to missing values.

${ }^{b}$ There were no missing values, so no imputations were made for these variables.

${ }^{c}$ Education is measured on a 5-level scale: (1) college or university (4 years or more); (2) college or university (less than 4 years); (3) high school diploma; (4) vocational school or technical school; and (5) primary and secondary school or similar (i.e., 7-10 years of schooling).

${ }^{d}$ The seven childhood adversities considered were: low mother's and father's education (parental primary and secondary school or similar), difficult or very difficult subjective childhood financial conditions. psychological abuse, physical abuse, substance abuse distress, and exposure to passive smoke in childhood.

eHSCL-10 (1.0-4.0), where 1.0 represents lowest score on anxious and depressive symptomatology, and 4.0 represents highest score on anxious and depressive symptomatology.

SE, standard error; HSCL-10, Hopkins Symptom Check List-10.

experienced at least one (Table 1). Almost one-third (29.0\%) of the participants were daily smokers, and the mean score on ADS was 1.25 (SE: 0.01) in Tromsø V (Table 1).

In the fully-adjusted model, childhood adversity was associated with a $10 \%$ higher risk of being a daily smoker in adulthood (RR: 1.10, 95\% CI: 1.03; 1.18) (Table 2). Moreover, in the fully-adjusted model, daily smoking in adulthood was associated with greater levels of ADS in adulthood ( $\beta$ : 0.07, $p<$ 0.001) (Table 3).

Table 4 presents the total effect, direct effect, indirect effect (via smoking in adulthood), and proportion of mediated effect (via smoking in adulthood) of childhood adversity on ADS in adulthood. After controlling for all the exposure-mediator, mediator-response, and exposure-response confounding variables considered in this study, childhood adversity was associated with greater levels of ADS in adulthood ( $\beta_{\text {Total Effect }}$ : 0.064, 95\% CI: 0.045 ; 0.083). Decomposition of total effects showed that almost all of the effect of childhood adversity was independent of smoking in adulthood ( $\beta_{\text {Direct Effect }}$ : $0.063,95 \%$ CI: $0.043 ; 0.078)$. Consequently, the indirect effect ( $\left.\beta_{\text {Indirect Effect: }} 0.001, p>0.05\right)$ and proportion of mediated effect (\% Proportion mediated: $1.30, p>0.05$ ) were not statistically significant (Table 4). 
TABLE 2 | Association between childhood adversity and smoking in adulthood $(n=4,530)$.

\begin{tabular}{|c|c|c|c|c|}
\hline & \multicolumn{4}{|c|}{ Smoking in adulthood } \\
\hline & \multicolumn{2}{|c|}{ Crude } & \multicolumn{2}{|c|}{ Adjusted $^{c}$} \\
\hline & $\mathbf{R R}$ & $95 \% \mathrm{Cl}$ & $\mathbf{R R}$ & $95 \% \mathrm{Cl}$ \\
\hline Childhood adversity & $1.09^{a}$ & $1.01,1.17$ & $1.10^{\mathrm{b}}$ & $1.03,1.18$ \\
\hline \multicolumn{5}{|c|}{$\begin{array}{l}{ }^{a} p<0.01 . \\
{ }^{b} p<0.001 . \\
{ }^{c} \text { Adjusted for age, gender, living in Norway at age } 1 \text { year, mother's/father's } \\
\text { history of psychological problems, parental history of heart attack/angina } \\
\text { pectoris cerebral stroke/brain hemorrhage/osteoporosis/stomach/duodenal ulcer } \\
\text { asthma/diabetes/dementia. } \\
R R \text {, relative risk; Cl, confidence interval. }\end{array}$} \\
\hline
\end{tabular}

TABLE 3 | Association between smoking and anxious and depressive symptomatology $(n=4,530)$.

\begin{tabular}{|c|c|c|c|c|}
\hline & \multicolumn{4}{|c|}{ Anxious and depressive symptomatology } \\
\hline & \multicolumn{2}{|c|}{ Crude } & \multicolumn{2}{|c|}{ Adjusted $^{\mathbf{b}}$} \\
\hline & $\beta$ & $95 \% \mathrm{Cl}$ & $\beta$ & $95 \% \mathrm{Cl}$ \\
\hline Smoking & $0.07^{a}$ & $0.05,0.10$ & $0.07^{\mathrm{a}}$ & $0.04,0.10$ \\
\hline
\end{tabular}

${ }^{a} p<0.001$.

${ }^{b}$ Adjusted for age, gender, living in Norway at age 1 year, parental education, subjective childhood financial conditions, psychological abuse in childhood, physical abuse in childhood, substance abuse distress in childhood, exposure to passive smoke in childhood, mother's/father's history of psychological problems, parental history of heart attack/angina pectoris/cerebral stroke/brain hemorrhage/osteoporosis/stomach/duodenal ulcer/asthma/diabetes/dementia, alcohol intake indicators, education, number of friends, and perceived social support.

$\mathrm{Cl}$, Confidence interval.

Smoking-ADS confounding factors (i.e., education, alcohol intake, and social support) were excluded from the models oneby-one, in order to assess how the indirect effect and proportion of mediated effect changed (Table 4). Excluding indicators of alcohol intake or social support did not change the inference, as the indirect effects and proportion of mediated effects were not statistically significant $(p>0.05)$. However, when education was excluded from the models, smoking in adulthood significantly (\%proportion mediated: 2.74, $p<0.05$ ) mediated the association between childhood adversity and ADS in adulthood (Table 4).

\section{DISCUSSION}

The results of this study show that childhood adversity is associated with an increased risk of smoking in adulthood, and smoking in adulthood is associated with greater levels of ADS in adulthood. The direct effects presented in this study show that the effects of childhood adversity on ADS in adulthood were slightly attenuated, but not eliminated, by adjustment for smoking in adulthood. Moreover, the results of this study show that a careful inclusion of mediator-response confounding variables is not only important for a "less" biased estimates of direct effect, indirect effect, and proportion of mediated effect, but also for the binary decision of whether there is an indirect effect based only on statistical significance. Indeed, if education was not measured or not considered as a potential confounder, a researcher relying on significance tests would conclude that smoking in adulthood significantly ( $p<0.05$, Table 4$)$ mediates the association between childhood adversity and ADS in adulthood.

Conditional on all the confounding variables considered in this study, smoking in adulthood did not significantly mediate the association between childhood adversity and ADS in adulthood. However, if excluding one mediator-response confounding variable (education) can make the indirect effect appear statistically significant, it is possible that including other confounding variables could also influence statistical significance. Similarly, it must be noted that despite accounting for several confounding variables and establishing temporality between smoking and ADS in adulthood, the indirect effects presented here cannot be interpreted as causal effects because there may be unmeasured (or unaccounted for) exposuremediator, mediator-response, or exposure-response confounding variables, as well as unmeasured intermediate confounding variables (Sheikh et al., 2016b; Sheikh, 2017). Although childhood adversity was the focus of the study, we cannot rule out that exposure to adverse events later in life might have affected smoking and ADS. Therefore, the results presented here do not "prove" that the indirect effect of childhood adversity on ADS via smoking is not causal, as the assumption of no unmeasured confounding is not satisfied, and may never be satisfied using an observational study design (Sheikh et al., 2016b; Sheikh, 2017). One might wonder what the purpose of such assumptions is if they are unlikely to be satisfied. We believe that the purpose, in practice, is to urge researchers to provide "as unbiased as feasible" estimates, instead of "as biased as possible" estimates. Unbiased estimates with a causal interpretation from observational studies represent an unattainable goal, but at least researchers can aim to reduce the "error" in estimates.

It must be noted that the inference regarding indirect effects is often based on statistical significance. This approach has been criticized, but for most journals publication of a manuscript relies (directly or indirectly) on statistical significance. This is why we chose to highlight the statistical significance in the contradictory inference drawn from indirect effects/proportion mediated effects when education is included or excluded from the models. If statistical significance is ignored, than all the indirect effects and proportion mediated effects in Table 4 provide the same information, i.e., some of the effect of childhood adversity on ADS in adulthood is mediated by smoking in adulthood, as the indirect effects were $>0$, and proportion mediated effects in all models were:

$$
0<\text { Proportion Mediated(\%) } \leq 100
$$

Consistent with previous studies, childhood adversity was associated with smoking in adulthood (Rohde et al., 2004; Le et al., 2016; Non et al., 2016) and with ADS in adulthood (Mauramo et al., 2012; Nurius et al., 2012; Quesnel-Vallée and Taylor, 2012; Baldassari et al., 2013; Kamiya et al., 2013; Oshio et al., 2013; Sperry and Widom, 2013; Torres and Wong, 2013; Ochi et al., 2014; Sheikh et al., 2014; Taha and Goodwin, 
TABLE 4 | Direct and indirect effect (via smoking) of childhood adversity on anxious and depressive symptomatology in adulthood $(n=4,530)$.

\begin{tabular}{|c|c|c|c|c|}
\hline & \multicolumn{4}{|c|}{ Adjusted for all Confounding Variables } \\
\hline & $\beta(95 \% \mathrm{Cl})$ & $\beta(95 \% \mathrm{Cl})$ & $\beta(95 \% \mathrm{Cl})$ & $\%(95 \% \mathrm{Cl})$ \\
\hline \multirow[t]{6}{*}{ Childhood adversity } & $0.064(0.045,0.083)^{a}$ & $0.063(0.043,0.078)^{b}$ & $0.001(-0.001,0.002)^{\mathrm{a}}$ & $1.30(-1.05,3.81)^{\mathrm{a}}$ \\
\hline & \multicolumn{4}{|c|}{ Excluding Education } \\
\hline & $0.069(0.040,0.085)^{\mathrm{e}}$ & $0.067(0.039,0.079)^{f}$ & $0.002(0.001,0.004)^{e}$ & $2.74(0.06,5.37)^{\mathrm{e}}$ \\
\hline & $0.064(0.044,0.081)^{\mathrm{C}}$ & $0.063(0.043,0.079)^{d}$ & $0.001(-0.001,0.002)^{\mathrm{c}}$ & $1.50(-0.50,4.20)^{\mathrm{C}}$ \\
\hline & \multicolumn{4}{|c|}{ Excluding Indicators of Social Support } \\
\hline & $0.074(0.055,0.092)^{9}$ & $0.074(0.054,0.089)^{h}$ & $0.001(-0.001,0.002)^{\mathrm{g}}$ & $1.05(-0.58,3.39)^{9}$ \\
\hline
\end{tabular}

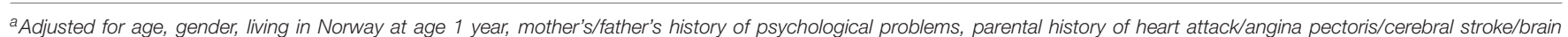
hemorrhage/osteoporosis/stomach/duodenal ulcer/ asthma/diabetes/dementia, education, number of friends, perceived social support, and indicators of alcohol intake.

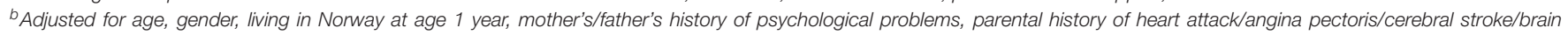

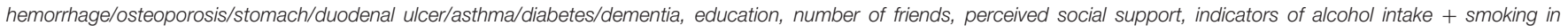
adulthood.

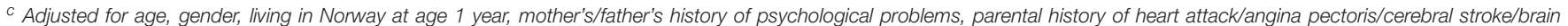
hemorrhage/osteoporosis/stomach/duodenal ulcer/asthma/diabetes/dementia, education, number of friends, and perceived social support.

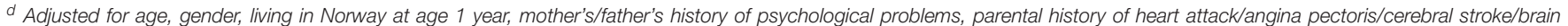
hemorrhage/osteoporosis/stomach/duodenal ulcer/asthma/diabetes/dementia, education, number of friends, and perceived social support + smoking in adulthood.

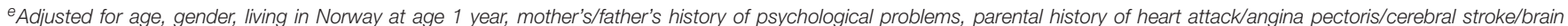
hemorrhage/osteoporosis/stomach/duodenal ulcer/asthma/diabetes/dementia, number of friends, perceived social support, and indicators of alcohol intake.

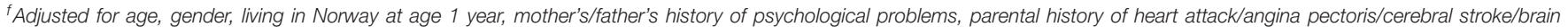
hemorrhage/osteoporosis/stomach/duodenal ulcer/asthma/diabetes/dementia, number of friends, perceived social support, indicators of alcohol intake + smoking in adulthood.

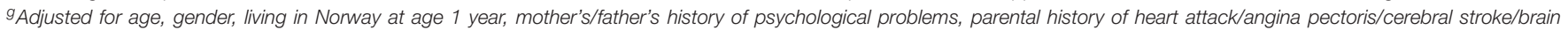
hemorrhage/osteoporosis/ stomach/duodenal ulcer/asthma/diabetes/dementia, education, number of friends, perceived social support, and indicators of alcohol intake.

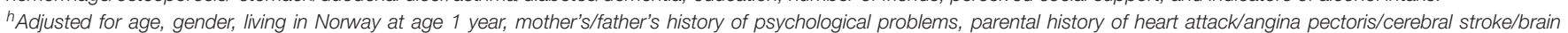

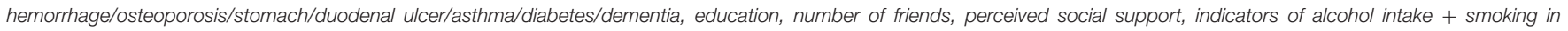
adulthood.

Cl, Confidence interval

2014). Similarly, and consistent with most (Jorm et al., 1999; Johnson et al., 2000; Martini et al., 2002; Nicolosi et al., 2004; Boden et al., 2010; Sheikh et al., 2014, 2016a), though not all (Kendler et al., 1993b; Albers and Biener, 2002; Nabi et al., 2010) previous studies, smoking in adulthood was associated with ADS in adulthood. Several previous studies (Kendler et al., 1993b; Albers and Biener, 2002; Fergusson et al., 2003) have suggested that including potential confounding variables in the models substantially reduces the strength of association between smoking and ADS. However, the strength of association between smoking and ADS remained similar in this study, despite adjusting for a wide range of confounding variables. Contrary to some studies (Sheikh et al., 2014), though not all (Gilman et al., 2002; Park et al., 2013; Sheikh et al., 2016a; Dahl et al., 2017; Sheikh, 2017), no statistically significant interaction was observed between childhood adversity and gender. Similarly, contrary to some previous studies (Lin et al., 2014), no statistically significant interaction between smoking and gender was observed in this sample. Furthermore, age (cohort effect Etherington, 2017) did not play a moderating role in the associations between childhood adversity, smoking, and ADS in adulthood (data not shown), which is in contrast to some (Goosby, 2013; Schaan, 2014), though not all (Raposo et al., 2014; Sheikh et al., 2014, 2016a,b; Sheikh, 2017) previous studies.

Statistically, the change in the estimate for an exposure due to a confounder or a mediator may be assessed in the same manner (with either the difference method or with statistical methods based on counterfactuals/potential outcomes) (Sheikh et al., 2016b). Therefore, the estimates for direct effects can be interpreted as an alternative hypothesis of whether childhood adversity affects ADS in adulthood, independent of smoking. This interpretation is sometimes preferred (instead of mediation hypothesis) for two reasons: first, smoking tends to be affected by parental behavioral patterns irrespective of psychosocial and socioeconomic conditions in childhood (Broms et al., 2012). Therefore, some of the association between childhood adversity and ADS may be driven by the association between parental behavioral patterns (Taha and Goodwin, 2014), and participants' smoking behavior. Second, the association between smoking and ADS may be reciprocal. For instance, smoking may be used to alleviate feelings of depression due to serotonergic dysfunctions (Stahl, 2013). Childhood adversity could negatively influence anxiety and depression in adolescence (Raposa et al., 2014; Wirback et al., 2014; Heshmat et al., 2016; Seijo et al., 2016; Björkenstam et al., 2017; Kang et al., 2017), which in turn may influence smoking behavior in adulthood. Indeed, history of anxiety and depression is also a strong predictor of anxiety and depression in later-life (Guerra et al., 2009; Din and Noor, 2010; Chen et al., 2012; Björkenstam et al., 2015; Davies et al., 2015).

The test-retest reliability of some variables was not very good in this study sample. The unreliability of confounding variables would imply that the total effects, direct effects, 
indirect effects and proportion of mediated effects are overestimated (biased upwards) (Sheikh et al., 2016b). However, the unreliability of mediator (smoking) would imply that the indirect effects and proportion of mediated effects are underestimated (biased downwards) (Sheikh et al., 2016b). Several studies have shown that retrospective measurement of childhood adversity is fairly reliable and valid (Krieger et al., 1998; Ward, 2011; Goodman et al., 2016). Other studies have shown that the association between retrospectively measured childhood adversity and ADS in adulthood is not driven by differential recall bias (Brown et al., 2007; Fergusson et al., 2011; Sheikh, 2017). The adverse effects of smoking are in part a function of the number of cigarettes smoked and duration of smoking. As this analysis did not have data on the amount or duration of smoking, the indirect effects could be biased downwards (under-estimated). The follow-up period between smoking and ADS was only 7 years; therefore, it is plausible that smoking may mediate the childhood adversity-ADS association over a longer period of time. No other psychometric scales were measured in the Tromsø Study and ADS was not measured in the Tromsø IV Study. Including ADS from an earlier wave (Tromsø IV) could strengthen the argument that smoking contributes a unique variance to subsequent $\mathrm{ADS}$ in Tromsø $\mathrm{V}$. The strengths of this study are its longitudinal design

\section{REFERENCES}

Agerup, T., Lydersen, S., Wallander, J., and Sund, A. M. (2015). Maternal and paternal psychosocial risk factors for clinical depression in a Norwegian community sample of adolescents. Nord. J. Psychiatry 69, 35-41. doi: 10.3109/08039488.2014.919021

Albers, A. B., and Biener, L. (2002). The role of smoking and rebelliousness in the development of depressive symptoms among a cohort of Massachusetts adolescents. Prev. Med. 34, 625-631. doi: 10.1006/pmed.2002.1029

Anda, R. F., Croft, J. B., Felitti, V. J., Nordenberg, D., Giles, W. H., and Williamson, D. F. (1999). Adverse childhood experiences and smoking during adolescence and adulthood. JAMA 282, 1652-1658. doi: 10.1001/jama.282.17.1652

Ary, D. V., Duncan, T. E., Duncan, S. C., and Hops, H. (1999). Adolescent problem behavior: the influence of parents and peers. Behav. Res. Ther. 37, 217-230. doi: 10.1016/S0005-7967(98)00133-8

Baldassari, A. R., Cleveland, R. J., and Callahan, L. F. (2013). Independent influences of current and childhood socioeconomic status on health outcomes in a North Carolina family practice sample of arthritis patients. Arthritis Care Res. (Hoboken). 65, 1334-1342. doi: 10.1002/acr.21969

Balevich, E. C., Wein, N. D., and Flory, J. D. (2013). Cigarette smoking and measures of impulsivity in a college sample. Subst. Abuse 34, 256-262. doi: 10.1080/08897077.2012.763082

Banou, E., Hobfoll, S. E., and Trochelman, R. D. (2009). Loss of resources as mediators between interpersonal trauma and traumatic and depressive symptoms among women with cancer. J. Health Psychol. 14, 200-214. doi: $10.1177 / 1359105308100204$

Bet, P. M., Penninx, B. W. J. H., Bochdanovits, Z., Uitterlinden, A. G., Beekman, A. T. F., van Schoor, N. M., et al. (2009). Glucocorticoid receptor gene polymorphisms and childhood adversity are associated with depression: new evidence for a gene-environment interaction. Am. J. Med. Genet. B Neuropsychiatr. Genet. 150B, 660-669. doi: 10.1002/ajmg.b.30886

Björkenstam, E., Burström, B., Brännström, L., Vinnerljung, B., Björkenstam, C., and Pebley, A. R. (2015). Cumulative exposure to childhood stressors and subsequent psychological distress. an analysis of US panel data. Soc. Sci. Med. 142, 109-117. doi: 10.1016/j.socscimed.2015.08.006 and a large representative sample of the adult population of Tromsø.

In summary, the results of this study suggest that childhood adversity is associated with greater levels of anxiety and depression in adulthood, and this association was not mediated significantly by smoking in adulthood.

\section{AUTHOR CONTRIBUTIONS}

The author confirms being the sole contributor of this work and approved it for publication.

\section{FUNDING}

This research was funded by the University of Tromsø. The publication charges for this article have been funded by a grant from the publication fund of UiT The Arctic University of Norway.

\section{ACKNOWLEDGMENTS}

I am thankful to Prof. Jan Abel Olsen and Dr. Birgit Abelsen for their contributions and collaboration throughout the project that resulted in this manuscript.

Björkenstam, E., Pebley, A. R., Burström, B., and Kosidou, K. (2017). Childhood social adversity and risk of depressive symptoms in adolescence in a US national sample. J. Affect. Disord. 212, 56-63. doi: 10.1016/j.jad.2017. 01.035

Boden, J. M., Fergusson, D. M., and Horwood, L. J. (2010). Cigarette smoking and depression: tests of causal linkages using a longitudinal birth cohort. $\mathrm{Br}$. J. Psychiatry 196, 440-446. doi: 10.1192/bjp.bp.109.065912

Broms, U., Koskenvuo, K., Sillanmäki Lauri, H., Mattila Kari, J., and Koskenvuo, M. (2012). Best friend's and family members' smoking habits and parental divorce during childhood are associated with smoking in adulthood. Nordic Stud. Alcohol Drugs 29, 441-452. doi: 10.2478/v10199-012-0039-2

Brown, G. W., Craig, T. K. J., Harris, T. O., Handley, R. V., and Harvey, A. L. (2007). Validity of retrospective measures of early maltreatment and depressive episodes using the childhood experience of care and abuse (CECA) instrument - a life-course study of adult chronic depression - 2. J. Affect. Disord. 103, 217-224. doi: 10.1016/j.jad.2007.06.003

Campbell, J. A., Walker, R. J., and Egede, L. E. (2016). Associations between adverse childhood experiences, high-risk behaviors, and morbidity in adulthood. Am. J. Prev. Med. 50, 344-352. doi: 10.1016/j.amepre.2015.07.022

Chen, Z. Y., Liu, R. X., and Kaplan, H. B. (2012). Early depressogenic effects of receiving negative parenting on adult affective disturbance. Adv. Life Course Res. 17, 210-219. doi: 10.1016/j.alcr.2012.05.002

Cole, S. R., and Hernán, M. A. (2002). Fallibility in estimating direct effects. Int. J. Epidemiol. 31, 163-165. doi: 10.1093/ije/31.1.163

Comijs, H. C., Beekman, A. T. F., Smit, F., Bremmer, M., Tilburg, T. V., and Deeg, D. J. H. (2007). Childhood adversity, recent life events and depression in late life. J. Affect. Disord. 103, 243-246. doi: 10.1016/j.jad.2007.01.012

Dahl, S. K., Larsen, J. T., Petersen, L., Ubbesen, M. B., Mortensen, P. B., MunkOlsen, T., et al. (2017). Early adversity and risk for moderate to severe unipolar depressive disorder in adolescence and adulthood: a register-based study of 978, 647 individuals. J. Affect. Disord. 214, 122-129. doi: 10.1016/j.jad.2017. 03.014

Davies, S. J. C., Pearson, R. M., Stapinski, L., Bould, H., Christmas, D. M., Button, K. S., et al. (2015). Symptoms of generalized anxiety disorder but not panic disorder at age 15 years increase the risk of depression at 18 years in the avon 
longitudinal study of parents and children (ALSPAC) cohort study. Psychol. Med. 46, 73-85. doi: 10.1017/S003329171500149X

Din, M. O., and Noor, N. M. (2010). Prevalence and factors associated with depressive symptoms in Malay women. Women Health 49, 573-591. doi: $10.1080 / 03630240903495897$

Donovan, J. E., and Jessor, R. (1985). Structure of problem behavior in adolescence and young adulthood. J. Consult. Clin. Psychol. 53, 890-904. doi: 10.1037/0022-006X.53.6.890

Dvir, Y., Ford, J. D., Hill, M., and Frazier, J. A. (2014). Childhood maltreatment, emotional dysregulation, and psychiatric comorbidities. Harv. Rev. Psychiatry 22, 149-161. doi: 10.1097/HRP.0000000000000014

Elder, G. H. J. (1985). "Perspectives on the life course," in Life Course Dynamics: Trajectories and Transitions, 1968-1980, eds G. H. J. Elder and S. S. R Council (New York, NY: Cornell University Press), 23-49.

Etherington, N. (2017). Re-evaluating gender differences in self-rated health: the importance of cohort. J. Women Aging 29, 150-162. doi: 10.1080/08952841.2016.1108737

Eugenia Alvarado, B., Victoria Zunzunegui, M., Béland, F., Sicotte, M., and Tellechea, L. (2007). Social and gender inequalities in depressive symptoms among urban older adults of latin America and the Caribbean. J. Gerontol. Ser. B 62, S226-S236. doi: 10.1093/geronb/62.4.S226

Fandiño-Losada, A., Bangdiwala, S. I., Lavebratt, C., and Forsell, Y. (2016). Path analysis of the chronicity of depression using the comprehensive developmental model framework. Nord. J. Psychiatry 70, 380-391. doi: 10.3109/08039488.2015.1134651

Fergusson, D. M., Goodwin, R. D., and Horwood, L. J. (2003). Major depression and cigarette smoking: results of a 21-year longitudinal study. Psychol. Med. 33, 1357-1367. doi: 10.1017/S0033291703008596

Fergusson, D. M., Horwood, L. J., and Boden, J. M. (2011). Structural equation modeling of repeated retrospective reports of childhood maltreatment. Int. J. Methods Psychiatr. Res. 20, 93-104. doi: 10.1002/mpr.337

Fleiss, J. L., Levin, B., and Paik, M. C. (2003). Statistical Methods for Rates and Proportions. Hoboken, NJ: John Wiley \& Sons.

Fluharty, M., Taylor, A. E., Grabski, M., and Munaf,ò, M. R. (2016). The association of cigarette smoking with depression and anxiety: a Systematic review. Nicotine Tob. Res. 19, 3-13. doi: 10.1093/ntr/ntw140

Ford, E., Clark, C., and Stansfeld, S. A. (2011). The influence of childhood adversity on social relations and mental health at mid-life. J. Affect. Disord. 133, 320-327. doi: 10.1016/j.jad.2011.03.017

Fuller-Thomson, E., Filippelli, J., and Lue-Crisostomo, C. A. (2013). Genderspecific association between childhood adversities and smoking in adulthood: findings from a population-based study. Public Health 127, 449-460. doi: $10.1016 /$ j.puhe.2013.01.006

Gilman, S. E., Abrams, D. B., and Buka, S. L. (2003). Socioeconomic status over the life course and stages of cigarette use: initiation, regular use, and cessation. J. Epidemiol. Commun. Health 57, 802-808. doi: 10.1136/jech.57.10.802

Gilman, S. E., Kawachi, I., Fitzmaurice, G. M., and Buka, S. L. (2002). Socioeconomic status in childhood and the lifetime risk of major depression. Int. J. Epidemiol. 31, 359-367. doi: 10.1093/intjepid/31.2.359

Gilman, S. E., Martin, L. T., Abrams, D. B., Kawachi, I., Kubzansky, L., Loucks, E. B., et al. (2008). Educational attainment and cigarette smoking: a causal association? Int. J. Epidemiol. 37, 615-624. doi: 10.1093/ije/ dym 250

Goodman, G. S., Goldfarb, D., Quas, J. A., Narr, R. K., Milojevich, H., and Cordon, I. M. (2016). "Memory development, emotion regulation, and traumarelated psychopathology," in Developmental Psychopathology, ed D. Cicchetti (Hoboken, NJ: John Wiley \& Sons, Inc.), 555-590.

Goosby, B. J. (2013). Early life course pathways of adult depression and chronic pain. J. Health Soc. Behav. 54, 75-91. doi: 10.1177/0022146512475089

Gould, J. W., and Martindale, D. A. (2007). The Art and Science of Child Custody Evaluations. New York, NY: Guilford Press.

Guerra, M., Ferri, C. P., Sosa, A. L., Salas, A., Gaona, C., Gonzales, V., et al. (2009). Late-life depression in Peru, Mexico and Venezuela: the 10/66 populationbased study. Br. J. Psychiatry 195, 510-515. doi: 10.1192/bjp.bp.109.064055

Haustein, K.-O. (2006). Smoking and poverty. Eur. J. Cardiovasc. Prev. Rehabil. 13, 312-318. doi: 10.1097/00149831-200606000-00004

Heim, C., and Binder, E. B. (2012). Current research trends in early life stress and depression: review of human studies on sensitive periods, gene-environment interactions, and epigenetics. Exp. Neurol. 233, 102-111. doi: 10.1016/j.expneurol.2011.10.032

Heshmat, R., Qorbani, M., Ghoreshi, B., Djalalinia, S., Tabatabaie, O. R., Safiri, S., et al. (2016). Association of socioeconomic status with psychiatric problems and violent behaviours in a nationally representative sample of Iranian children and adolescents: the CASPIAN-IV study. BMJ Open 6:e011615. doi: 10.1136/bmjopen-2016-011615

Hill, T. D., Kaplan, L. M., French, M. T., and Johnson, R. J. (2010). Victimization in early life and mental health in adulthood. J. Health Soc. Behav. 51, 48-63. doi: $10.1177 / 0022146509361194$

Jackson, K. M., Colby, S. M., and Sher, K. J. (2010). Daily patterns of conjoint smoking and drinking in college student smokers. Psychol. Addict. Behav. 24, 424-435. doi: 10.1037/a0019793

Jacobsen, B. K., Eggen, A. E., Mathiesen, E. B., Wilsgaard, T., and Njølstad, I. (2012). Cohort profile: the tromsø study. Int. J. Epidemiol. 41, 961-967. doi: $10.1093 /$ ije/dyr049

Johnson, J. G., Cohen, P., Pine, D. S., Klein, D. F., Kasen, S., and Brook, J. S. (2000). Association between cigarette smoking and anxiety disorders during adolescence and early adulthood. JAMA 284, 2348-2351. doi: 10.1001/jama.284.18.2348

Jorm, A. F., Rodgers, B., Jacomb, P. A., Christensen, H., Henderson, S., and Korten, A. E. (1999). Smoking and mental health: results from a community survey. Med. J. Aust. 170, 74-77.

Kamiya, Y., Doyle, M., Henretta, J. C., and Timonen, V. (2013). Depressive symptoms among older adults: the impact of early and later life circumstances and marital status. Aging Ment. Health 17, 349-357. doi: $10.1080 / 13607863.2012 .747078$

Kang, H., Chung, I.-J., Chun, J., Nho, C. R., and Woo, S. (2017). Linking traumatic childhood experiences to the physical health of Korean adolescents in outof-home care through depression and anxiety. Soc. Work Public Health 32, 122-130. doi: 10.1080/19371918.2016.1230082

Kaplow, J. B., and Widom, C. S. (2007). Age of onset of child maltreatment predicts long-term mental health outcomes. J. Abnorm. Psychol. 116, 176-187. doi: 10.1037/0021-843X.116.1.176

Kaslow, N. J., Deering, C. G., and Racusin, G. R. (1994). Depressed children and their families. Clin. Psychol. Rev. 14, 39-59. doi: 10.1016/0272-7358(94)90047-7

Kauhanen, L., Leino, J., Lakka, H. M., Lynch, J. W., and Kauhanen, J. (2011). Adverse childhood experiences and risk of binge drinking and drunkenness in middle-aged finnish men. Adv. Prev. Med. 2011:12. doi: 10.4061/2011/478741

Kendler, K. S., Neale, M. C., Kessler, R. C., Heath, A. C., and Eaves, L. J. (1993a). The lifetime history of major depression in women: reliability of diagnosis and heritability. Arch. Gen. Psychiatry 50, 863-870. doi: 10.1001/archpsyc. 1993.01820230054003

Kendler, K. S., Neale, M. C., MacLean, C. J., Heath, A. C., Eaves, L. J., and Kessler, R. C. (1993b). Smoking and major depression: a causal analysis. Arch. Gen. Psychiatry 50, 36-43. doi: 10.1001/archpsyc.1993.01820130038007

Kestilä, L., Koskinen, S., Martelin, T., Rahkonen, O., Pensola, T., Pirkola, S., et al. (2006). Influence of parental education, childhood adversities, and current living conditions on daily smoking in early adulthood. Eur. J. Public Health 16, 617-626. doi: 10.1093/eurpub/ckl054

Kim, J., and Cicchetti, D. (2010). Longitudinal pathways linking child maltreatment, emotion regulation, peer relations, and psychopathology. J. Child Psychol. Psychiatry 51, 706-716. doi: 10.1111/j.1469-7610.2009.02202.x

Kim, S.-S., Jang, H., Chang, H. Y., Park, Y. S., and Lee, D.-W. (2013). Association between childhood adversities and adulthood depressive symptoms in South Korea: results from a nationally representative longitudinal study. BMJ Open 3:e002680. doi: 10.1136/bmjopen-2013-002680

Korhonen, K., Remes, H., and Martikainen, P. (2017). Education as a social pathway from parental socioeconomic position to depression in late adolescence and early adulthood: a finnish population-based register study. Soc. Psychiatry Psychiatr. Epidemiol. 52, 105-116. doi: 10.1007/s00127-016-1296-2

Korkeila, J., Vahtera, J., Nabi, H., Kivimäki, M., Korkeila, K., Sumanen, M., et al. (2010). Childhood adversities, adulthood life events and depression. J. Affect. Disord. 127, 130-138. doi: 10.1016/j.jad.2010.04.031

Krieger, N., Okamoto, A., and Selby, J. V. (1998). Adult female twins recall of childhood social class and father's education: a validation study for public health research. Am. J. Epidemiol. 147, 704-708. doi: 10.1093/oxfordjournals.aje.a009512 
Kvamme, J.-M., Grønli, O., Florholmen, J., and Jacobsen, B. K. (2011). Risk of malnutrition is associated with mental health symptoms in community living elderly men and women: the tromsø study. BMC Psychiatry 11:112. doi: 10.1186/1471-244X-11-112

Kwon, E., and Park, S. (2017). Heterogeneous trajectories of physical and mental health in late middle age: importance of life-course socioeconomic positions. Int. J. Environ. Res. Public Health 14:582. doi: 10.3390/ijerph14060582

Lahelma, E., Laaksonen, M., Martikainen, P., Rahkonen, O., and SarlioLähteenkorva, S. (2006). Multiple measures of socioeconomic circumstances and common mental disorders. Soc. Sci. Med. 63, 1383-1399. doi: 10.1016/j.socscimed.2006.03.027

Lau, J. T. F., Liu, J. L. Y., Cheung, J. C. K., Yu, A., and Wong, C. K. (1999). Prevalence and correlates of physical abuse in Hong Kong Chinese adolescents: a population-based approach. Child Abuse Negl. 23, 549-557. doi: 10.1016/S0145-2134(99)00029-0

Lee, C., Glei, D. A., Goldman, N., and Weinstein, M. (2017). Children's education and parents' trajectories of depressive symptoms. J. Health Soc. Behav. 58, 86-101. doi: 10.1177/0022146517690200

Lemos, V. A., Antunes, H. K. M., Baptista, M. N., Tufik, S., De Mello, M. T., and de Souza Formigoni, M. L. O. (2012). Low family support perception: a 'social marker' of substance dependence? Rev. Bras. Psiquiatry 34, 52-59. doi: 10.1016/S1516-4446(12)70010-7

Lê-Scherban, F., Brenner, A. B., and Schoeni, R.F. (2016). Childhood family wealth and mental health in a national cohort of young adults. SSM Popul. Health 2, 798-806. doi: 10.1016/j.ssmph.2016.10.008

Le, T. L., Mann, R. E., Levitan, R. D., George, T. P., and Maunder, R. G. (2016). Sex differences in the relationships between childhood adversity, attachment anxiety and current smoking. Addict. Res. Theory 25, 146-153. doi: 10.1080/16066359.2016.1233968

Lin, F.-G., Chou, Y.-C., Wu, C.-H., and Lin, J.-D. (2014). Short-term and longterm influences of family arguments and gender difference on developing psychological well-being in Taiwanese adolescents. Res. Dev. Disabil. 35, 2735-2743. doi: 10.1016/j.ridd.2014.07.018

MacKinnon, D. P., Fairchild, A. J., and Fritz, M. S. (2007). Mediation analysis. Annu. Rev. Psychol. 58, 593-614. doi: 10.1146/annurev.psych.58.110405.085542

Markkula, N., Marola, N., Nieminen, T., Koskinen, S., Saarni, S. I., Härkänen, T., et al. (2017). Predictors of new-onset depressive disorders - results from the longitudinal finnish health 2011 Study. J. Affect. Disord. 208, 255-264. doi: 10.1016/j.jad.2016.08.051

Martini, S., Wagner, F. A., and Anthony, J. C. (2002). The association of tobacco smoking and depression in adolescence: evidence from the United States. Subst. Use Misuse 37, 1853-1867. doi: 10.1081/JA-120014087

Mauramo, E., Lallukka, T., Laaksonen, M., Martikainen, P., Rahkonen, O., and Lahelma, E. (2012). Past and present socioeconomic circumstances and psychotropic medication: a register-linkage study. J. Epidemiol. Community Health 66, 1143-1151. doi: 10.1136/jech-2011-200036

McEwen, B. S. (2000). Allostasis and allostatic load: implications for neuropsychopharmacology. Neuropsychopharmacology 22, 108-124. doi: 10.1016/S0893-133X(99)00129-3

McGuffin, P., Katz, R., Watkins, S., and Rutherford, J. (1996). A hospital-based twin registery study of the heritability of DSM-IV unipolar depression. Arch. Gen. Psychiatry 53, 129-136. doi: 10.1001/archpsyc.1996.01830020047006

Mckenzie, S., Carter, K., Blakely, T., and Ivory, V. (2011). Effects of childhood socioeconomic position on subjective health and health behaviours in adulthood: how much is mediated by adult socioeconomic position? BMC Public Health 11:269. doi: 10.1186/1471-2458-11-269

McKenzie, S. K., Carter, K., Blakely, T., and Collings, S. (2010). The association of childhood socio-economic position and psychological distress in adulthood: is it mediated by adult socio-economic position? Longit. Life Course Stud. 1:20. doi: 10.14301/llcs.v1i4.126

Melas, P. A., Wei, Y., Wong, C. C. Y., Sjöholm, L. K., Åberg, E., Mill, J., et al. (2013). Genetic and epigenetic associations of MAOA and NR3C1 with depression and childhood adversities. Int. J. Neuropsychopharmacol. 16, 1513-1528. doi: 10.1017/S1461145713000102

Mersky, J. P., Topitzes, J., and Reynolds, A. J. (2013). Impacts of adverse childhood experiences on health, mental health, and substance use in early adulthood: a cohort study of an urban, minority sample in the U.S. Child Abuse Negl. 37, 917-925. doi: 10.1016/j.chiabu.2013.07.011
Miller, G. E., Chen, E., and Parker, K. J. (2011). Psychological stress in childhood and susceptibility to the chronic diseases of aging: moving towards a model of behavioral and biological mechanisms. Psychol. Bull. 137, 959-997. doi: $10.1037 /$ a0024768

Mitchell, M. R., and Potenza, M. N. (2014). Addictions and personality traits: impulsivity and related constructs. Curr. Behav. Neurosci. Rep. 1, 1-12. doi: 10.1007/s40473-013-0001-y

Moretti, M. M., and Craig, S. G. (2013). Maternal versus paternal physical and emotional abuse, affect regulation and risk for depression from adolescence to early adulthood. Child Abuse Negl. 37, 4-13. doi: 10.1016/j.chiabu.2012. 09.015

Mossakowski, K. N. (2008). Dissecting the influence of race, ethnicity, and socioeconomic status on mental health in young adulthood. Res. Aging 30, 649-671. doi: 10.1177/0164027508322693

Muller, P. A. (2016). The effects of adversity on depression among university students. J. Educ. Soc. Res. 6, 53-62. doi: 10.5901/jesr.2016.v6n2p53

Mulvihill, D. (2005). The health impact of childhood trauma: an interdisciplinary review, 1997-2003. Issues Compr. Pediatr. Nurs. 28, 115-136. doi: 10.1080/01460860590950890

Nabi, H., Singh-Manoux, A., Ferrie, J., Marmot, M., Melchior, M., and Kivimäki, M. (2010). Hostility and depressive mood: results from the whitehall II prospective cohort study. Psychol. Med. 40, 405-413. doi: 10.1017/S0033291709990432

Ni, M. Y., Jiang, C., Cheng, K. K., Zhang, W., Gilman, S. E., Lam, T. H., et al. (2016). Stress across the life course and depression in a rapidly developing population: the Guangzhou biobank cohort study. Int. J. Geriatr. Psychiatry 31, 629-637. doi: 10.1002/gps.4370

Nicholson, A., Pikhart, H., Pajak, A., Malyutina, S., Kubinova, R., Peasey, A., et al. (2008). Socio-economic status over the life-course and depressive symptoms in men and women in eastern Europe. J. Affect. Disord. 105, 125-136. doi: $10.1016 /$ j.jad.2007.04.026

Nicolosi, A., Moreira, Jr, E. D., Villa, M., and Glasser, D. B. (2004) A population study of the association between sexual function, sexual satisfaction and depressive symptoms in men. J. Affect. Disord. 82, 235-243. doi: 10.1016/j.jad.2003.12.008

Non, A. L., Román, J. C., Gross, C. L., Gilman, S. E., Loucks, E. B., Buka, S. L., et al. (2016). Early childhood social disadvantage is associated with poor health behaviours in adulthood. Ann. Hum. Biol. 43, 144-153. doi: 10.3109/03014460.2015.1136357

Nurius, P. S., Green, S., Logan-Greene, P., and Borja, S. (2015). Life course pathways of adverse childhood experiences toward adult psychological well-being: a stress process analysis. Child Abuse Negl. 45, 143-153. doi: 10.1016/j.chiabu.2015.03.008

Nurius, P. S., Green, S., Logan-Greene, P., Longhi, D., and Song, C. (2016). Stress pathways to health inequalities: embedding ACEs within social and behavioral contexts. Int. Public Health J. 8, 241-256.

Nurius, P. S., Logan-Greene, P., and Green, S. (2012). Adverse childhood experiences (ACE) within a social disadvantage framework: distinguishing unique, cumulative, and moderated contributions to adult mental health. J. Prev. Interv. Community 40, 278-290. doi: 10.1080/10852352.2012. 707443

Ochi, M., Fujiwara, T., Mizuki, R., and Kawakami, N. (2014). Association of socioeconomic status in childhood with major depression and generalized anxiety disorder: results from the world mental health Japan survey 2002-2006. BMC Public Health 14:359. doi: 10.1186/1471-2458-14-359

Openshaw, M., Thompson, L. M., Pheils, P. B., Mendoza-Flores, M. E., and Humphreys, J. (2015). Childhood trauma is associated with depressive symptoms in Mexico City women. Rev. Panam. Salud Pública 37, 308-315. Available online at: http://www.scielosp.org/pdf/rpsp/v37n4-5/v37n4-5a18.pdf

Oshio, T., Umeda, M., and Kawakami, N. (2013). Impact of interpersonal adversity in childhood on adult mental health: how much is mediated by social support and socio-economic status in Japan? Public Health 127, 754-760. doi: 10.1016/j.puhe.2013.05.005

Park, A., Fuhrer, R., and Quesnel-Vallée, A. (2013). Parents' education and the risk of major depression in early adulthood. Soc. Psychiatry Psychiatr. Epidemiol. 48, 1829-1839. doi: 10.1007/s00127-013-0697-8

Patten, S. B., Wilkes, T. C. R., Williams, J. V. A., Lavorato, D. H., el-Guebaly, N., Wild, T. C., et al. (2016). Childhood adversity and subsequent mental 
health status in adulthood: screening for associations using two linked surveys. Epidemiol. Psychiatr. Sci. 25, 160-170. doi: 10.1017/S2045796015000104

Pearlin, L. I., Schieman, S., Fazio, E. M., and Meersman, S. C. (2005). Stress, health, and the life course: some conceptual perspectives. J. Health Soc. Behav. 46, 205-219. doi: 10.1177/002214650504600206

Plant, D. T., Pariante, C. M., Sharp, D., and Pawlby, S. (2015). Maternal depression during pregnancy and offspring depression in adulthood: role of child maltreatment. Br. J. Psychiatry 207, 213-220. doi: 10.1192/bjp.bp.114. 156620

Pollak, S. D. (2008). Mechanisms linking early experience and the emergence of emotions: illustrations from the study of maltreated children. Curr. Dir. Psychol. Sci. 17, 370-375. doi: 10.1111/j.1467-8721.2008.00608.x

Power, C., and Hertzman, C. (1997). Social and biological pathways linking early life and adult disease. Br. Med. Bull. 53, 210-221. doi: 10.1093/oxfordjournals.bmb.a011601

Powers, A., Ressler, K. J., and Bradley, R. G. (2009). The protective role of friendship on the effects of childhood abuse and depression. Depress. Anxiety 26, 46-53. doi: 10.1002/da.20534

Prock, L. A. (2015). The Societal Burden of Child Abuse: Long-term Mental Health and Behavioral Consequences. Oakville, ON: Apple Academic Press.

Quesnel-Vallée, A., and Taylor, M. (2012). Socioeconomic pathways to depressive symptoms in adulthood: evidence from the national longitudinal survey of youth 1979. Soc. Sci. Med. 74, 734-743. doi: 10.1016/j.socscimed.2011. 10.038

Raposa, E. B., Hammen, C. L., Brennan, P. A., O'Callaghan, F., and Najman, J. M. (2014). Early adversity and health outcomes in young adulthood: the role of ongoing stress. Health Psychol. 33, 410-418. doi: 10.1037/a0032752

Raposo, S. M., Mackenzie, C. S., Henriksen, C. A., and Afifi, T. O. (2014). Time does not heal all wounds: older adults who experienced childhood adversities have higher odds of mood, anxiety, and personality disorders. Am. J. Geriatr. Psychiatry 22, 1241-1250. doi: 10.1016/j.jagp.2013.04.009

Reichenheim, M. E. (2004). Confidence intervals for the kappa statistic. Stata J. 4, 421-428. Available online at: http://www.stata-journal.com/sjpdf.html? articlenum $=$ st0076

Repetti, R. L., Taylor, S. E., and Seeman, T. E. (2002). Risky families: Family social environments and the mental and physical health of offspring. Psychol. Bull. 128, 330-366. doi: 10.1037/0033-2909.128.2.330

Robbins, R. N., and Bryan, A. (2004). relationships between future orientation, impulsive sensation seeking, and risk behavior among adjudicated adolescents. J. Adolesc. Res. 19, 428-445. doi: 10.1177/0743558403258860

Robins, J. M., and Greenland, S. (1992). Identifiability and exchangeability for direct and indirect effects. Epidemiology 3, 143-155. doi: 10.1097/00001648-199203000-00013

Rohde, P., Kahler, C. W., Lewinsohn, P. M., and Brown, R. A. (2004). Psychiatric disorders, familial factors, and cigarette smoking: II. associations with progression to daily smoking. Nicotine Tob. Res. 6, 119-132. doi: $10.1080 / 14622200310001656948$

Salazar, A. M., Keller, T. E., and Courtney, M. E. (2011). Understanding social support's role in the relationship between maltreatment and depression in youth with foster care experience. Child Maltreat. 16, 102-113. doi: $10.1177 / 1077559511402985$

Schaan, B. (2014). The interaction of family background and personal education on depressive symptoms in later life. Soc. Sci. Med. 102, 94-102. doi: 10.1016/j.socscimed.2013.11.049

Seijo, D., Fariña, F., Corras, T., Novo, M., and Arce, R. (2016). Estimating the epidemiology and quantifying the damages of parental separation in children and adolescents. Front. Psychol. 7:1611. doi: 10.3389/fpsyg.2016.01611

Sheikh, M. A. (2017). Childhood adversities and chronic conditions: Examination of mediators, recall bias and age at diagnosis. Int. J. Public Health. doi: 10.1007/ s00038-017-1021-2

Sheikh, M. A., Abelsen, B., and Olsen, J. A. (2014). Role of respondents' education as a mediator and moderator in the association between childhood socioeconomic status and later health and wellbeing. BMC Public Health 14:1172. doi: 10.1186/1471-2458-14-1172

Sheikh, M. A., Abelsen, B., and Olsen, J. A. (2016a). Clarifying associations between childhood adversity, social support, behavioral factors, and mental health, health, and well-being in adulthood: a population-based study. Front. Psychol. 7:727. doi: 10.3389/fpsyg.2016.00727
Sheikh, M. A., Abelsen, B., and Olsen, J. A. (2016b). Differential recall bias, intermediate confounding, and mediation analysis in life course epidemiology: an analytic framework with empirical example. Front. Psychol. 7:1828. doi: $10.3389 /$ fpsyg.2016.01828

Sheikh, M. A., Lund, E., and Braaten, T. (2016c). Test-retest reliability of selfreported diabetes diagnosis in the Norwegian women and cancer study: a population-based longitudinal study $(\mathrm{n}=33,919)$. SAGE Open Medicine 4, 1-11. doi: $10.1177 / 2050312115622857$

Shevlin, M., McElroy, E., and Murphy, J. (2015). Loneliness mediates the relationship between childhood trauma and adult psychopathology: evidence from the adult psychiatric morbidity survey. Soc. Psychiatry Psychiatr. Epidemiol. 50, 591-601. doi: 10.1007/s00127-014-0951-8

Shiffman, S., Fischer, L. A., Paty, J. A., and Gnys, M. (1994). Drinking and smoking: a field study of their association. Ann. Behav. Med. 16, 203-209.

Shrout, P. E., and Bolger, N. (2002). Mediation in experimental and nonexperimental studies: new procedures and recommendations. Psychol. Methods 7, 422-445. doi: 10.1037/1082-989X.7.4.422

South, S. C., Schafer, M. H., and Ferraro, K. F. (2015). Genetic and environmental overlap between childhood maltreatment and adult physical health. Twin Res. Human Genet. 18, 533-544. doi: 10.1017/thg.2015.62

Sperry, D. M., and Widom, C. S. (2013). Child abuse and neglect, social support, and psychopathology in adulthood: a prospective investigation. Child Abuse Negl. 37, 415-425. doi: 10.1016/j.chiabu.2013.02.006

Spratt, E. G., Back, S. E., Yeatts, S. D., Simpson, A. N., McRae-Clark, A., MoranSanta Maria, M. M., et al. (2009). Relationship between child abuse and adult smoking. Int. J. Psychiatry Med. 39, 417-426. doi: 10.2190/PM.39.4.f

Stahl, S. M. (2013). Stahl's Essential Psychopharmacology: Neuroscientific Basis and Practical Applications. Cambridge, MA: Cambridge University Press.

Stautz, K., Pechey, R., Couturier, D.-L., Deary, I. J., and Marteau, T. M. (2016). Do executive function and impulsivity predict adolescent health behaviour after accounting for intelligence? findings from the ALSPAC cohort. PLOS ONE 11:e0160512. doi: 10.1371/journal.pone.0160512

Stikkelbroek, Y., Bodden, D. H. M., Kleinjan, M., Reijnders, M., and van Baar, A. L. (2016). Adolescent depression and negative life events, the mediating role of cognitive emotion regulation. PLoS ONE 11:e0161062. doi: 10.1371/journal.pone.0161062

Strand, B. H., Dalgard, O. S., Tambs, K., and Rognerud, M. (2003). Measuring the mental health status of the Norwegian population: a comparison of the instruments SCL-25, SCL-10, SCL-5 and MHI-5 (SF-36). Nord. J. Psychiatry 57, 113-118. doi: 10.1080/08039480310000932

Strine, T. W., Edwards, V. J., Dube, S. R., Wagenfeld, M., Dhingra, S., Prehn, A. W., et al. (2012). The mediating sex-specific effect of psychological distress on the relationship between adverse childhood experiences and current smoking among adults. Subst. Abuse Treat. Prev. Policy 7:30. doi: 10.1186/1747-597X-7-30

Taha, F., and Goodwin, R. D. (2014). Secondhand smoke exposure across the life course and the risk of adult-onset depression and anxiety disorder. J. Affect. Disord. 168, 367-372. doi: 10.1016/j.jad.2014.07.014

Tani, Y., Fujiwara, T., Kondo, N., Noma, H., Sasaki, Y., and Kondo, K. (2016). Childhood Socioeconomic status and onset of depression among Japanese older adults: the JAGES prospective cohort study. Am. J. Geriatr. Psychiatry 24, 717-726. doi: 10.1016/j.jagp.2016.06.001

Torres, J. M., and Wong, R. (2013). Childhood poverty and depressive symptoms for older adults in mexico: a life-course analysis. J. Cross Cult. Gerontol. 28, 317-337. doi: 10.1007/s10823-013-9198-1

VanderWeele, T. J. (2015). Explanation in Causal Inference: Methods for Mediation and Interaction. New York, NY: Oxford University Press.

VanderWeele, T. J., and Arah, O. A. (2011). Bias formulas for sensitivity analysis of unmeasured confounding for general outcomes, treatments, and confounders. Epidemiology 22, 42-52. doi: 10.1097/EDE.0b013e3181f74493

Vranceanu, A.-M., Hobfoll, S. E., and Johnson, R. J. (2007). Child multitype maltreatment and associated depression and PTSD symptoms: the role of social support and stress. Child Abuse Negl. 31, 71-84. doi: $10.1016 /$ j.chiabu.2006.04.010

Warburton, D. M. (1987). "The functions of smoking," in Tobacco Smoking and Nicotine: A Neurobiological Approach, eds W. R. Martin, G. R. Van Loon, E. T. Iwamoto, and L. Davis (Boston, MA: Springer US), 51-61. 
Ward, M. M. (2011). Concordance of sibling's recall of measures of childhood socioeconomic position. BMC Med. Res. Methodol. 11:147. doi: 10.1186/1471-2288-11-147

Wender, P. H., Kety, S. S., Rosenthal, D., Schulsinger, F., Ortmann, J., and Lunde, I. (1986). Psychiatric disorders in the biological and adoptive families of adopted individuals with affective disorders. Arch. Gen. Psychiatry 43, 923-929. doi: 10.1001/archpsyc.1986.01800100013003

Wielaard, I., Comijs, H. C., Stek, M. L., and Rhebergen, D. (2017). Childhood abuse and the two-year course of late-life depression. Am. J. Geriatr. Psychiatry 25, 633-643. doi: 10.1016/j.jagp.2017.01.014

Wirback, T., Möller, J., Larsson, J.-O., Galanti, M. R., and Engström, K. (2014). Social factors in childhood and risk of depressive symptoms among adolescents - a longitudinal study in Stockholm, Sweden. Int. J. Equity Health 13:96. doi: 10.1186/s12939-014-0096-0
Zou, G. (2004). A modified poisson regression approach to prospective studies with binary data. Am. J. Epidemiol. 159, 702-706. doi: 10.1093/aje/ kwh090

Conflict of Interest Statement: The author declares that the research was conducted in the absence of any commercial or financial relationships that could be construed as a potential conflict of interest.

Copyright (C) 2017 Sheikh. This is an open-access article distributed under the terms of the Creative Commons Attribution License (CC BY). The use, distribution or reproduction in other forums is permitted, provided the original author(s) or licensor are credited and that the original publication in this journal is cited, in accordance with accepted academic practice. No use, distribution or reproduction is permitted which does not comply with these terms. 